\title{
A comparison of health data from River Forth pilots in Scotland: in 1988 and 2012
}

\section{Philip Rutledge}

\author{
Public Health Consultant, Edinburgh, United Kingdom
}

\begin{abstract}
Background: Marine pilots are a special group of seafarers who live ashore and work on board only when piloting. Few studies have reported on their health.

Aim: The aim of this study is to compare the health data collected during routine medical examinations in 1988 and 2012.

Materials and methods: Data collected from medical examinations of 44 marine pilots in 1988 were compared with data collected from 27 marine pilots in 2012. These data were compared with general population and maritime studies.

Results: There was a reduction in number of pilots who smoked, from $41 \%$ to $7 \%$. Small improvements in health risk factors were found in reported alcohol intake, prescribed medication, blood pressure and urinalysis. There was an increase in the number of pilots classed as overweight or obese from $45 \%$ to $67 \%$. Conclusions: Observed changes suggest that pilots in 2012 have less cardiovascular risk than pilots in 1988. Smoking levels in River Forth Pilots reduced from 41\% to 7\% between 1988 and 2012. If the Maritime and Coastguard Agency were to collect and store routine health data electronically, rather than on paper, a large database of seafarers' health data could be analysed in the future.
\end{abstract}

(Int Marit Health 2014; 65, 2: 43-46)

Key words: marine pilots, routine health data, medical examinations, cardiovascular risk factors

\section{INTRODUCTION}

Several studies have documented that seafarers have higher mortality and are at greater risk of cardiovascular disease than the general population and a recent literature review that included nearly 58,000 seafarers and fishermen confirmed the high prevalence of cardiovascular risk factors in these workers [1]. Marine pilots (pilots) are a special group of seafarers who live ashore and work on board only when piloting. In the 1970s, studies in English and German pilots suggested that pilots had increased mortality from ischaemic heart disease similar to seafarers, but in the 1990s, Finnish and Swedish studies reported pilots' mortality to be the same as the general population [2-5]. In 2012, a US study on inland waterway marine captains and pilots found a high prevalence of smoking, obesity and associated cardiometabolic risk factors [6].

River Forth pilots protect the shores and neighbouring urban environments of the Firth of Forth Estuary near Edin- burgh, capital of Scotland, by ensuring that merchant ships navigate and arrive at their destination safely without mishap. Pilots meet and board ships at the mouth of the Forth estuary and assist ships' captains in navigating and berthing their vessels (container ships, oil and gas tankers, cargo boats, passenger ships, etc.) at their designated harbour, dock, anchorage or oil terminal. Similarly they complete the reverse exercise when vessels head out of the estuary to the North Sea and beyond.

The importance of the role of the pilot is highlighted when there are accidents and these can have considerable harmful effects on the surrounding areas and the population. Notable examples have been the oil spills associated with the M/V "Sea Empress" near Milford Haven in 1996 and M/V "Cosco Busan" near San Francisco in 2007 [7, 8].

The aim of this study is to compare the health data collected during routine medical examinations in 1988 and 2012. 


\section{PARTICIPANTS}

All the River Forth Pilots are experienced master mariners who have previously worked in the merchant navy. The skill of pilotage requires a combination of local knowledge, expertise, experience, communication skills and crew management. The job of the pilot has changed little in the last 30 years despite some technology improvements such as GPS, automatic vessel identification systems, communications and improved weather forecasting. In rough weather the pilots' job can be physically challenging as it involves transfer between large ships and a small pilot cutter while at sea. In most instances this is still undertaken using a rope ladder without a safety harness. Marine traffic operates 24 hours a day so pilots work a shift system.

Forth pilots have complied with the Medical Standards of Fitness for Seafarers and undergone routine 2 yearly medical examinations by an Approved Doctor to the standards determined by the Maritime and Coastguard Agency (MCA) [9]. Data on their health have been collected at each examination on a standard form (called ENG2) devised for this purpose.

There were 44 pilots working in 1988 and 27 pilots employed in 2012. There were fewer pilots involved in 2012 because of a gradual change to larger merchant ships and also a subsequent change in the pilots working rota. No pilots working in 1988 were working in 2012. All the pilots working on the River Forth are British and male. In the UK approximately $1 \%$ of marine pilots are female.

\section{MATERIALS AND METHODS}

All the medical examination records (ENG2 forms) were identified for the 44 pilots working in 1988 and the 27 pilots employed in 2012. Health data under 10 headings had been collected and recorded in the same way. These were: age, height, weight, smoking status, alcohol intake, whether on prescribed medication, systolic blood pressure, diastolic blood pressure, and urinalysis for protein and glucose. Body mass index (BMI) was calculated from height and weight information available.

The author recorded all data at the 2012 medical examinations and the majority of those from 1988 . There was a high level of consistency in recording with no missing data in the ten health parameters identified.

\section{RESULTS}

Table 1 shows that the two groups have similar average age and average BMI. The average BMI was 26 but there were a greater number of overweight and obese pilots in 2012, 67\% compared to $45 \%$ in 1988.

Smoking $-41 \%$ of 1988 pilots were current smokers compared to 7\% in 2012.

The prevalence of smoking and levels of overweight and obesity were compared with data from the local population in Edinburgh, Lothian area, and also with data from maritime studies (Figs. 1, 2).

It can also be seen from Table 1 that there is a reduction in alcohol intake, average blood pressure, prescribed medication, and detected glycosuria and proteinuria.

\section{DISCUSSION}

The observed reduction in smoking, alcohol intake and blood pressure, which are established markers for cardiovascular disease risk, in conjunction with other improved health improvements such as lower prescribed medication,

Table 1. Health data from pilot group 1988 and pilot group 2012

\begin{tabular}{lll}
\hline Data & Pilot group 1988 & Pilot group 2012 \\
\hline Number of forms & 44 & 27 \\
Age - average [years] (range) & $53(41-63)$ & $50(36-61)$ \\
Height - average [cm] (range) & $176(162-186)$ & $179(168-189)$ \\
Weight - average [kg] (range) & $79(62-100)$ & $84(70-103)$ \\
Body mass index - average (range) & $26(19-33)$ & $26(21-32)$ \\
Body mass index > 25 (overweight or obese) & $45 \%(20 / 44)$ & $67 \%(18 / 27)$ \\
Current smokers & $41 \%$ & $7 \%$ \\
Alcohol - average [units/week] (range) & $15(0-50)$ & $11(0-25)$ \\
Receiving prescribed medication & $36 \%(16 / 44)$ & $30 \%(8 / 27)$ \\
Systolic blood pressure - average [mm Hg] (range) & $149(110-230)$ & $130(98-153)$ \\
Diastolic blood pressure - average [mm Hg] (range) & $76(60-120)$ & $84(64-113)$ \\
Urinalysis (dipstix) for protein & $5 \%(2 / 44)$ & $0(0 / 27)$ \\
Urinalysis (dipstix) for glucose & $5 \%(2 / 44)$ & $0(0 / 27)$
\end{tabular}




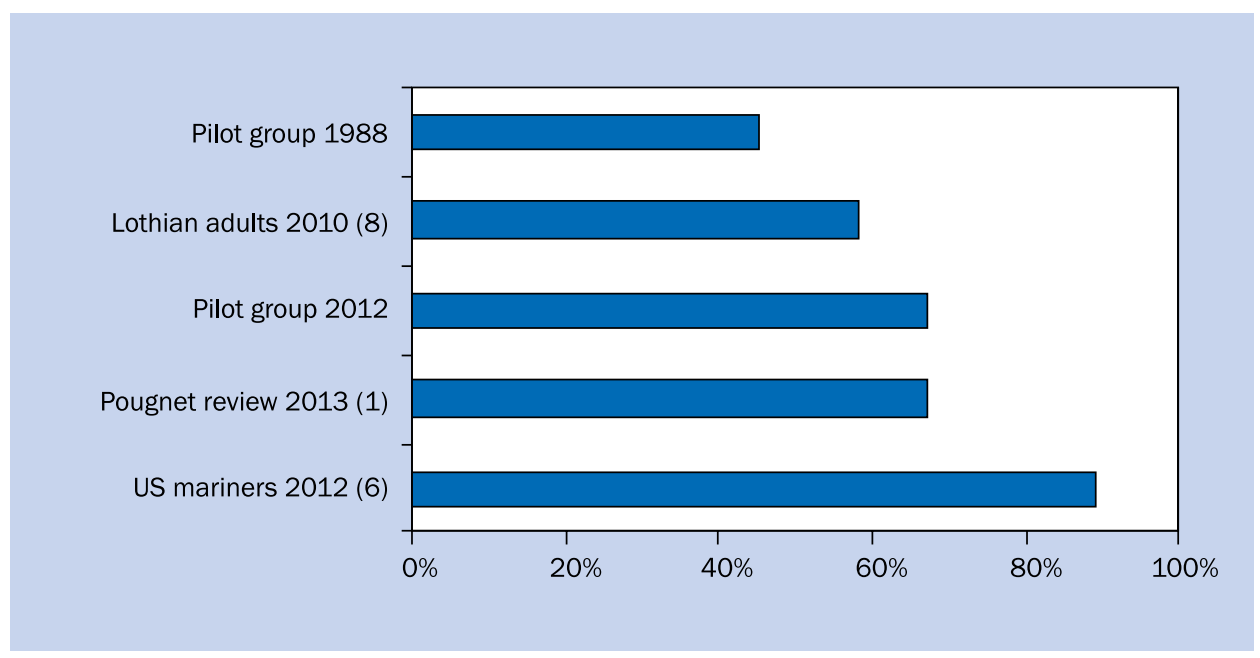

Figure 1. Overweight or obese - body mass index $>25$

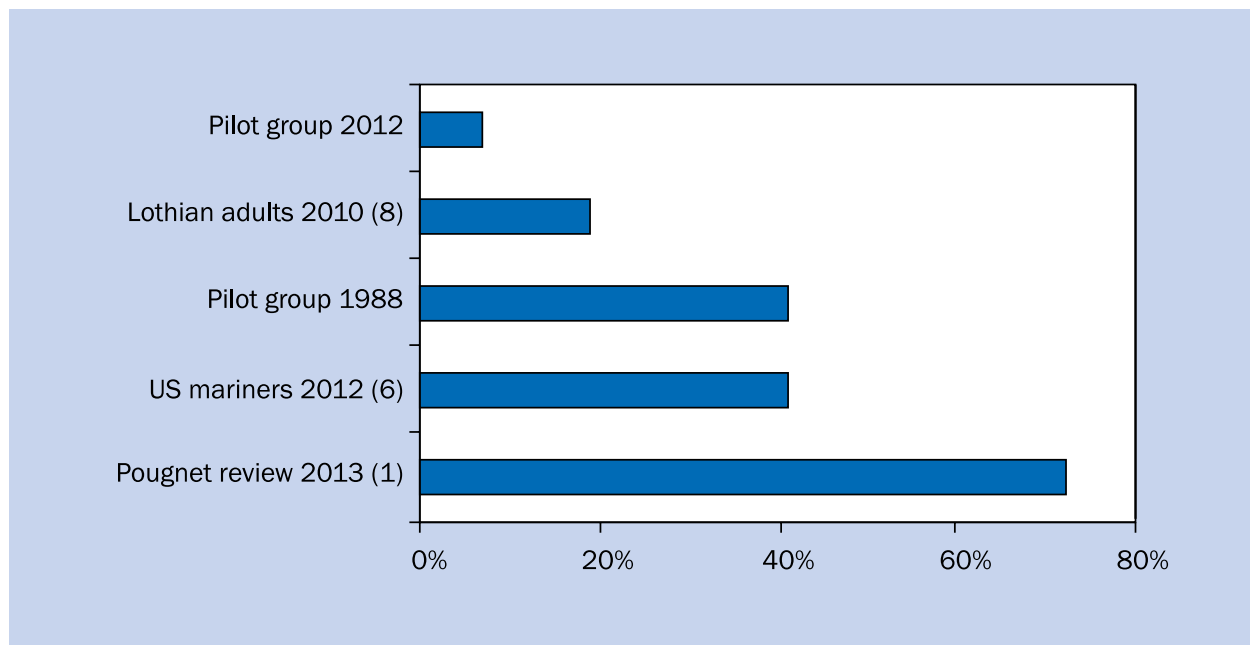

Figure 2. Smoking prevalence

absence of proteinuria and glycosuria, suggest that 2012 pilots have lower cardiovascular risk than 1988 pilots.

The most striking difference between the two groups is the prevalence of smoking, $41 \%$ in 1988 pilots compared to $7 \%$ in 2012 pilots. The level of $7 \%$ current smokers in 2012 compares favourably with the level of $19 \%$ found in the Lothian Health and Lifestyle Survey in 2010 [10]. 41\% found in a US study in 2012 [6], and $37-72 \%$ in the literature review by Pougnet et al. [1] (Fig. 2).

Scotland is experiencing high levels of obesity [11]. In this study, $45 \%$ of 1988 pilots were either overweight (BMI 25-30) or obese (BMI > 30) compared to 67\% in 2012 pilots. This compares with $58 \%$ from Lothian adults in 2010 [10], 28-67\% from the Pougnet et al. review [1] and 89\% from the US study of 388 inland waterway merchant marine captains and pilots in 2012 [6] (Fig. 1).
The strength of this study lies in the fact that data were collected and recorded in a consistent manner on a standardised form. The weakness of the study is that the numbers in each group are small. The smoking status, alcohol units and prescribed medication levels were those recorded after discussion with the examining doctor. Therefore as in all studies with self-reported details, the actual levels may be different.

In 2012 there were 52,200 MCA medical examinations performed by approved doctors worldwide, and the information recorded on paper forms. If the data were recorded on computer a very large database could be examined over time to monitor health trends. There is also the potential to identify other issues, such as results on fitness to work, any work restrictions on location, type of employment, and ill health retirement. 
The 2012 pilots have an average age of 50 years and $67 \%$ are overweight or obese. The observed higher BMI in 2012 pilots is concerning as they have a physical component to their job when boarding and disembarking from vessels at sea. In rough weather this can be a challenging task to perform and potentially places them at risk unless they are physically strong and agile. This raises the question about their physical fitness and whether the periodical medical examination should include an agility or fitness test. In 1992 Saarni et al. [12] suggested that medical examinations of sea pilots should pay more attention to prevention of overweight, effective treatment of musculoskeletal symptoms, improving physical working capacity and helping pilots to manage their psychic stress. My experience from working with this special group is that most pilots would resist any proposal to change their medical examination. They would argue that they can tell when they are unable to perform their job and would not attempt a difficult transfer between vessels in rough weather if they felt it was unsafe. Certainly a high level of confidence in both their physical ability and in their decision making is an essential skill for the specialised job of a river pilot.

\section{CONCLUSIONS}

Observed changes suggest that pilots in 2012 have less cardiovascular risk than pilots in 1988. Smoking levels in River Forth Pilots reduced from $41 \%$ to $7 \%$ between 1988 and 2012. If the MCA were to collect and store routine health data electronically, rather than on paper, a large database of seafarers' health data could be analysed in the future.

\section{ACKNOWLEDGMENTS}

The author wishes to thank Dr T. Carter, Chief Medical Adviser, MCA - Seafarer Safety and Health Branch, Southampton UK, for general advice on the content and write up of the study, Captain J. Hague, Chair Forth Pilots
Association for general information about UK pilots, and all current and retired members of the Forth Pilots Association for their cooperation over the last 30 years.

\section{CONFLICTS OF INTEREST}

The author is paid for providing medical advice to Forth Ports Ltd and is an Approved Doctor for the MCA to conduct medical examinations for seafarers in the UK.

\section{REFERENCES}

1. Pougnet $R$, Pougnet $L$, Lodde B etal. Cardiovascular risk factors in seamen and fishermen: review of literature. Int Marit Health 2013; 64: 107-113.

2. Harrington JM. Mortality from coronary heart disease of English Channel and Hamburg pilots. Trans Soc Occup Med 1972; 22: 19-23.

3. Zorn E, Seifert R. Catecholamine excretion in marine pilots. Agressiologie 1977; 18: 269-272.

4. Saarni H, Niemi L, Koskela R-S, Pentti J, Kuusela A. Mortality among Finnish sea pilots 1956-1985: a retrospective cohort study. Occup Med 1996; 46: 281-284.

5. Nystrom L, Kolmodin B, Jonsson E, Thomasson L. Mortality from circulatory diseases, especially ischaemic heart disease in sea pilots and boatmen in Sweden 1951-1984: a retrospective cohort study. Br J Ind Med 1990; 47: 122-126.

6. Scovill SM, Roberts TK, McCarty DJ. Health characteristics of inland waterway merchant marine captains and pilots. Occup Med 2012; 62: 638-641.

7. Report of the Chief Inspector of Marine Accidents. Sea Empress at Milford haven. The Stationary Office 1997; ISBN 0115518908.

8. Incident Specific Preparedness Review (ISPR) M/V Cosco Busan Oil Spill in San Francisco Bay. Report 11 January 2008.

9. Maritime and Coastguard Agency MCA Southampton Approved Doctors Manual. Standards for seafarers: http://www.dft.gov.uk/ $\mathrm{mca}$ /mca_doctors_manual_links_.pdf.

10. Platt S, Forbes J, Mackie P. Lothian health and lifestyle survey (NHS Lothian 2009-2010).

11. Bromley C, Sharp C, Given L eds. The Scottish Health Survey 2011 (3 Volumes). The Scottish Government Health Directorate, Edinburgh 2012.

12. Saarni H, Niemi L, Pentti J, Hartiala J. Is there a need for change of health examinations for sea pilots? Bull Inst Marit Trop Med Gdynia 1992; 43: 25-34. 